\title{
Granuloma telangiectásico en cavidad oral. Reporte de un caso clínico
}

\section{Telangiecticum granuloma in oral cavity. Report of clinic case}

\section{Díaz Caballero AJ*, Vergara Hernández Cl**, Carmona Lorduy M***}

\section{RESUMEN}

El granuloma telangiectásico es un tumor benigno que se presenta en cavidad oral, frecuentemente observado en la zona anterior de la cavidad oral y en encía, sangrante y de crecimiento rápido, asociado a la presencia de irritantes locales. Su tratamiento es la escisión quirúrgica, aunque puede presentar recidiva. Dentro de sus diagnósticos diferenciales encontramos el granuloma periférico de células gigantes, hemangioma capilar adquirido, carcinoma epidermoide exofítico, carcinoma metastásico, sarcoma de Kaposi, fibroma periférico, tumores mesenquimales benignos y malignos. Se presenta caso clínico de paciente femenino de 52 años de edad que acudió a consulta odontológica en la facultad de Odontología de la Universidad de Cartagena por presentar dos lesiones tumorales que sangraban con facilidad ubicadas en encía papilar y espacio edéntulo relacionadas a prótesis parcial fija de tres unidades entre órganos dentarios 11-13. Se le realizó la escisión quirúrgica de la lesión y se envió a patología donde se confirmó histopatológicamente diagnóstico de granuloma telangiectásico.

Palabras clave: Granuloma telangiectásico, técnicas de diagnóstico quirúrgico, hiperplasia gingival.

\section{SUMMARY}

Telangiecticum granuloma is a benign tumor that occurs in the oral cavity, often observed in the anterior section of the oral cavity and gums, it is bleeding and rapid growth, associated with the presence of local irritants. Its treatment is surgical excision, but may present recurrence. Inside we find the differential diagnosis of peripheral giant cell granuloma, capillary hemangioma acquired exophytic squamous cell carcinoma, metastatic carcinoma, Kaposi's sarcoma, peripheral fibroma, benign and malignant mesenchymal tumors. In this paper is reported a case of female patient aged 52 who came to the Dental School of Dentistry of the University of Cartagena for filling 2 lesions that bled easily located in papillary gingiva and edentulous space fixed partial dentures related to three dental units between 11-13 bodies. Was performed surgical excision of the lesion and sent to pathology where histopathologically confirmed diagnosis of telangiecticum granuloma.

Key words: Granuloma telangiecticum, diagnostic techniques, surgical, gingival hyperplasia.

Fecha de recepción: 4 de marzo 2009.

Aceptado para publicación: 6 de marzo 2009.

* Odontólogo Universidad de Cartagena. Especialista en Periodoncia Universidad Javeriana. Magíster en Educación Universidad del Norte.

** Odontóloga Universidad de Cartagena. Especialista en Patología y Cirugía Oral Universidad Javeriana.

*** Odontóloga Universidad de Cartagena. Especialista en Estomatología Universidad de Buenos Aires Argentina.

Díaz Caballero AJ, Vergara Hernández CI, Carmona Lorduy M. Granuloma telangiectásico en cavidad oral. Reporte de un caso clínico. Av. Odontoestomatol 2009; 25 (3): 131-135. 


\section{INTRODUCCIÓN}

El granuloma telangiectásico es una lesión tumoral de tipo hiperplásico simple de células endoteliales reactivas y caracterizada por un tejido de granulación excedente semejante, por sus extensos y numerosos vasos sanguíneos, a la estructura de un hemangioma capilar (1). Generalmente aparecen sobre la encía, causados por estimulo o irritantes locales, cálculos o cuerpo extraño en los tejidos, márgenes desbordantes de coronas entre otros (2).

La etiología de la lesión es bastante discutida; Ponce y Dor, en 1897, expusieron que las lesiones encontradas en la piel de cuatro pacientes eran el producto de un contagio ocasionado por caballos castrados que mostraban lesiones semejantes y padecían una micosis denominada botriomicosis; de esta forma se le designó el nombre de botriomicosis humana a las lesiones observadas en estos pacientes (3).

El término granuloma piógeno fue aplicado por Hartzell en 1904 y es un nombre equivocado, pues se creía que era una infección por estafilococos o estreptococos ya que estos microorganismos producen colonias con características parecidas a los hongos, contrariamente a lo que el nombre implica, la lesión no contiene pus $(4,5)$

También es conocido como granuloma gravidarum (tumor del embarazo) el cual se desarrolla en las encías durante la etapa preadolescente, el embarazo o con el uso de anticonceptivos orales es decir relacionado con la ingesta de hormonas; es recidivante si se extirpa durante el embarazo y puede resolverse de forma espontánea después del parto. El incremento hormonal especialmente en el embarazo propicia el desarrollo del granuloma telangiectásico, especialmente en pacientes con irritantes locales (6). Esta lesión está presente en el 5\% de las mujeres durante el embarazo y puede desarrollarse en cualquier momento del mismo, lo más frecuente es que aparezca durante el primer o segundo mes del primer embarazo y suele desaparecer espontáneamente tras el parto si se eliminan los irritantes locales. En caso de ser necesaria la escisión quirúrgica, suele hacerse después del parto y solo se realiza durante el embarazo si causa alteraciones funcionales importantes o presenta sangrado profuso, aunque suele recidivar hasta que el embarazo finaliza (7)

Generalmente es localizado, pero en ocasiones puede hacerse difuso y manifestarse como una gingivitis hipertrófica hemorrágica. Con menos frecuencia esta lesión puede aparecer en la lengua (Fenton y cols., 1996) $(8,9)$.

En un estudio realizado por Ono Y. y cols. en el 2002 para investigar los rasgos clínicos detallados de enfermedades orales benignas con un total de 792 pacientes tratados con las lesiones orales benignas el Hospital Universitario Kitasato se encontró que el granuloma telangiectásico se encuentra en el $5 \%$ de las lesiones benignas en cavidad oral, en un rango de edad de 40-50 años, en proporción 1:1 hombre y mujeres, con 19 semanas de aparición de los síntomas y sitio más frecuente de aparición, lengua (10).

En un estudio de 108 casos en jordanos realizado por Al-khateeb y Ababneh en el período de 1991 a 2001; la edad de los pacientes fue de 3 a 85 años (promedio, 30 años), con el más alto grado de incidencia $(26,8 \%)$ en la segunda década. La proporción de varón a hembra era $1: 1,7$. El sitio más frecuentemente fue la gingiva $(44,4 \%)$ más prevalentes en el maxilar que en la mandíbula, con la región anterior de ambas mandíbulas que se afectan más frecuentemente. La queja principal fue el sangrado $(59,3 \%)$ y casi la mitad de las lesiones tenía base pediculada, con la ulceración de la superficie en 9,2\% de casos. El diámetro más grande del granuloma fue $10 \mathrm{~mm}$. Todas las lesiones fueron eliminadas quirúrgicamente, con 5,8\% de recurrencia (11).

El granuloma telangiectásico aparece predominantemente en las mujeres en la segunda década de vida. Clínicamente en cavidad oral aparece frecuentemente en el maxilar superior en región anterolabial de la encía (18), se presenta como una lesión rojo brillante, pediculada o sésil, cuyo tamaño va de pocos milímetros a centímetros. La superficie puede ser erosiva, sangran fácilmente y pueden crecer rápidamente $(19,20)$. Su evolución es autolimitada y tiende a desaparecer después de su exéresis y de la eliminación de los factores etiológicos (12). 
Aunque no tiene predilección de edad y puede presentarse durante la erupción dental. En cuanto a la raza el granuloma telangiectásico predomina en las personas de raza blanca (13).

En el examen histológico se observa una lesión bien delimitada, recubierta por endotelio adelgazado o ulcerado conformado por lóbulos de vasos capilares rodeados de infiltrado inflamatorio rico en Polimorfos nucleares neutrófilos. Por debajo del epitelio existe una gran proliferación de pequeños vasos capilares, de pared fina, dispuestos en islotes o lóbulos, rodeados por un tejido conectivo laxo y edematoso, que alberga una infiltración celular discreta o densa con frecuencia se observan fascículos de colágeno que atraviesan la masa del tejido (14).

El tratamiento incluye escisión, curetaje, escleroterapia, cauterización química y eléctrica, radioterapia y el uso de láser de $\mathrm{CO}_{2}$ para evitar su recidiva. Cuando el granuloma telangiectásico es grande, escoger un tratamiento adecuado puede ser difícil. La biopsia excisional esta indicada para el tratamiento de granuloma telangiectásico exceptuando los casos en que puede causar una deformidad marcada, en tal caso la biopsia incisional es obligatoria. Si la lesión es pequeña, menos dolorosa y sin hemorragia la observación clínica y el seguimiento son aconsejados. Así la escisión quirúrgica conservadora y la remoción de las causas irritantes (placa, cálculo, trauma, etc.) son tratamientos usuales para lesiones gingivales. La escisión debe extenderse por debajo del periostio y los dientes vecinos deben ser limpiados para remover las causas de irritación continua (15).

\section{CASO CLÍNICO}

Paciente de 59 años de edad femenina, sin antecedentes médicos de importancia, que acudió a consulta en abril del año 2007 por presentar dos tumoraciones hiperplásicas, sintomáticas, que sangran con facilidad.

$\mathrm{Al}$ interrogatorio la paciente refiere que hace aproximadamente 20 años le fue extraído órgano dentario anterosuperior derecho el cual fue remplazado por una prótesis parcial fija de tres unidades. Comentó que hace aproximadamente 2 años apareció tumo-

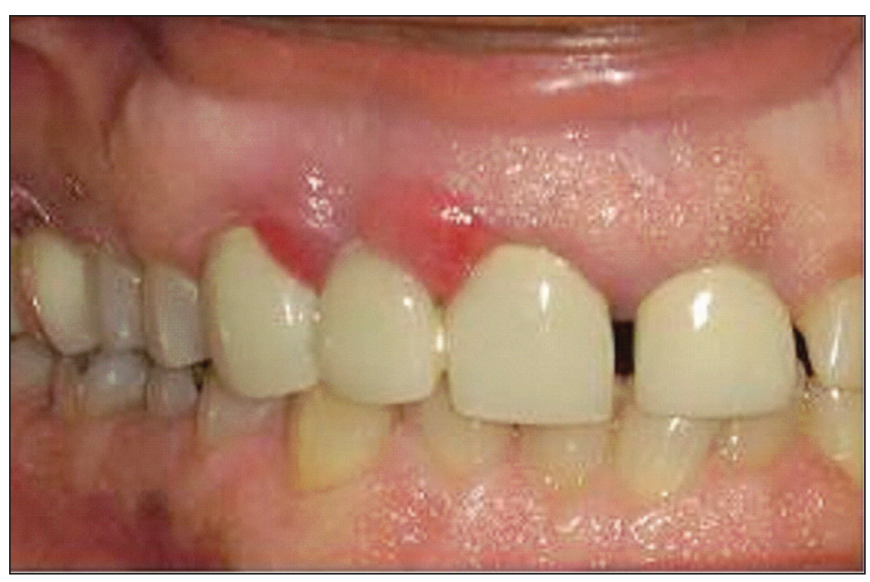

Fig.1. Tumoraciones hiperplásicas sangrantes ubicadas en encía del sector anterosuperior derecho.

ración hiperplásica en dicha zona. La cual fue extirpada quirúrgicamente, pero hace 4 meses aproximadamente ésta volvió a aparecer.

Al examen clínico se observaron dos tumoraciones hiperplásicas de color rojo vino de superficie rugosa, base sésil y consistencia firme, ubicadas en encía mesial de órgano dentario 13, mesial de órgano dentario 11 y espacio edéntulo de órgano dentario 12 de aproximadamente $7 \mathrm{~mm}$ y $9 \mathrm{~mm}$ de diámetro respectivamente, relacionadas con prótesis parcial fija de tres unidades cuyos pilares son los órganos den-

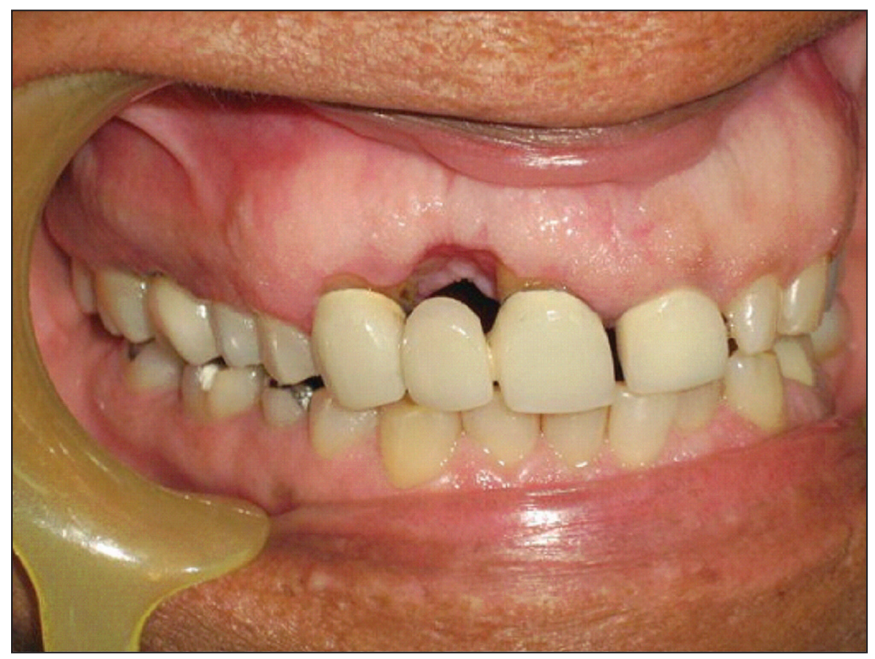

Fig. 2. Control postoperatorio de la paciente a los 15 días de la cirugía. 


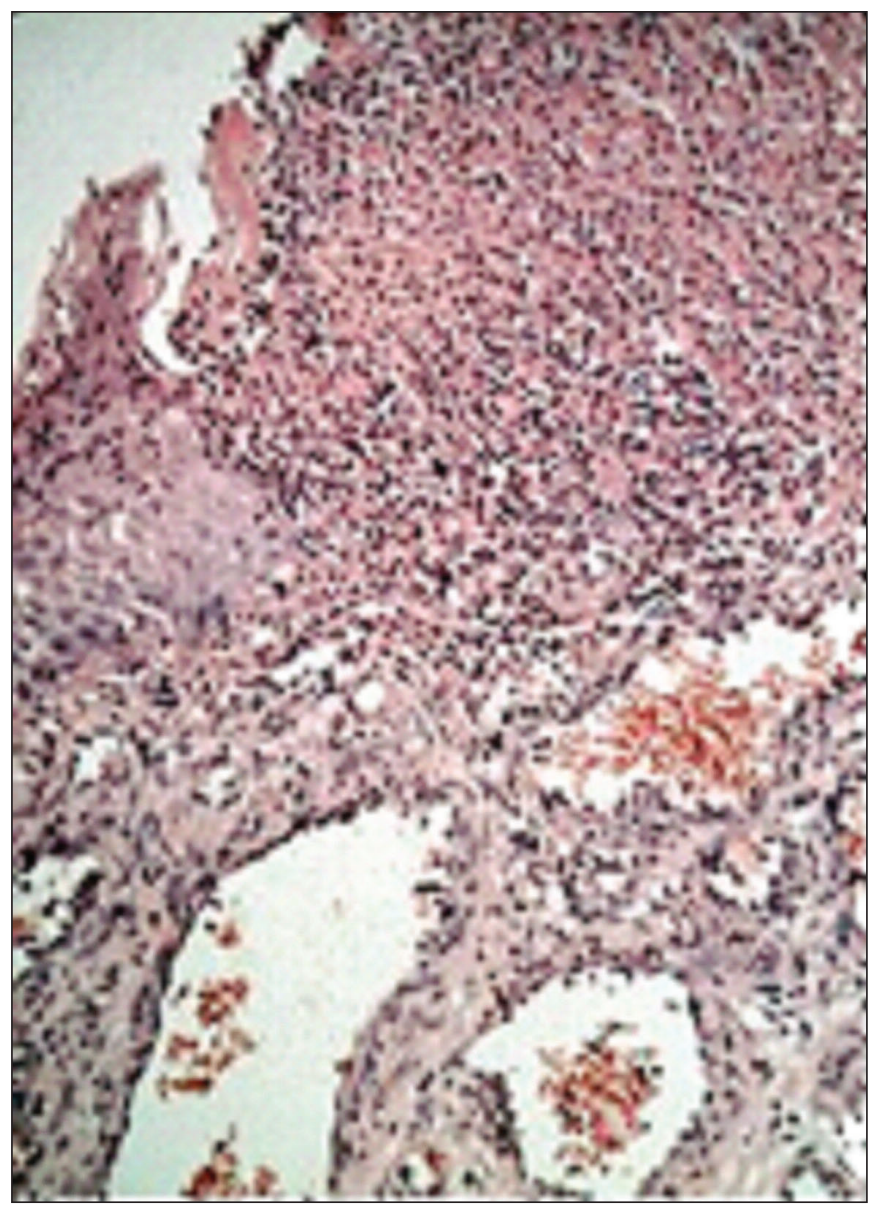

Fig. 3. Corte histológico de las lesiones extirpadas donde se aprecia una proliferación vascular con gran cantidad de neutrófilos e infiltrado inflamatorio crónico, tapizadas por mucosa sana. No se observa hueso comprometido por las lesiones. No se observa malignidad en la muestra examinada.

tarios de 11 y 13 . Al sondaje presentó bolsas periodontales de $10 \mathrm{~mm}$.

Previa anestesia infraorbitaria derecha, nasopalatina, espina nasal anterior e infiltrativas alrededor de la lesión, se realizó incisión a bisel interno alrededor de la lesión y se consiguió la escisión quirúrgica de esta, realizando un curetaje en la zona para evitar recidivas, se suturó con puntos en ocho y seda 4-0.

\section{DISCUSIÓN}

La paciente se ubica en la sexta década, de la vida a diferencia del estudio realizado por Al-khateeb y
Ababneh en el período de 1991 a 2001; en donde la edad con el más alto grado de incidencia $(26,8 \%)$ en la segunda década. Cabe destacar que en esta época hay alteraciones hormonales que coinciden con la etapa premenopáusica y menopáusica lo cual pudo originar la patología como lo afirma Díaz L, Castellanos J., en el 2004.

La lesión de este caso se ubica en encía papilar del sector anterosuperior derecho al igual que lo expresado por Regezi J. y Sciubba J., en el año 2003. Este dato difiere del estudio realizado por Ono Y. y cols., en el año 2002, quienes encontraron que el sitio más frecuente de aparición del granuloma telangiectásico es la lengua.

El síntoma principal de la paciente fue el dolor dato que no coincide con lo expresado por Al-khateeb y Ababneh en el período de 1991 a 2001 donde la queja principal fue el sangrado $(59,3 \%)$.

Clínicamente la presentación de la base de la lesión era de tipo sésil coincidiendo con Al-khateeb y Ababneh en el período de 1991 a 2001 donde más de la mitad de las lesiones tenía base sésil.

\section{BIBLIOGRAFÍA}

1. Jafarzadeh H, Sanatkhani M, Mohtasham N. J Oral Sci. Oral pyogenic granuloma: a review 2006 Dec; 48(4):167-75.

2. Zhang W, Chen Y, An Z, Geng N, Bao D. Quintessence Int., Reactive gingival lesions: a retrospective study of 2,439 cases 2007 Feb; 38(2):103-10.

3. Sánchez JG. Granuloma Piogénico. Reporte de dos casos de aparición inusual y revisión de la literatura. Acta Odontol Venez 2000 jun; 38(2):3640.

4. Parisi E, Glick PH, Glick M. Recurrent intraoral pyogenic granuloma with satellitosis treated with corticosteroids. Oral Dis 2006; 12:70-72.

5. Epivatianos A, Antoniades D, Zaraboukas T, Zairi E, Poulopoulos A, Kiziridou A, Iordanidis S. 
Pyogenic granuloma of the oral cavity: comparative study of its clinicopathological and immunohistochemical features. Pathol Int 2005 Jul;55(7):391-7.

6. Díaz-Guzmán LM, Castellanos-Suárez JL. Lesions of the oral mucosa and periodontal disease behavior in pregnant patients. Med Oral Patol Oral Cir Bucal 2004 Nov-Dec;9(5):434-7; 430-3.

7. Silk H, Douglass AB, Douglass JM, Silk L. Oral health during pregnancy. Am Fam Physician 2008 Apr 15;77(8):1139-44.

8. Silva-Sousa YT, Coelho CM, Brentegani LG, Vieira $M L$, de Oliveira ML. Clinical and histological evaluation of granuloma gravidarum: case report. Braz Dent J 2000;11(2):135-9.

9. Svirsky J. Oral pyogenic granuloma. J Indiana Dent Assoc. 2007 Spring;86(1):12-4.

10. Sheehan DJ, Lesher JL Jr. Pyogenic granuloma arising within a port-wine stain. Cutis 2004 Mar; 73(3): 175-80.

11. Al-Khateeb T, Ababneh K. Oral pyogenic granuloma in Jordanians: a retrospective analysis of 108 cases. J Oral Maxillofac Surg 2003 Nov;61 (11):1285-8.
12. Ramírez K, Bruce G, Carpenter W. Pyogenic granuloma: case report in a 9-year-old girl. Gen Dent 2002 May-Jun;50(3):280-1.

13. Salum FG, Yurgel LS, Cherubini K, De Figueiredo MA, Medeiros IC, Nicola FS. Pyogenic granuloma, peripheral giant cell granuloma and peripheral ossifying fibroma: retrospective analysis of 138 cases. Minerva Stomatol 2008 May;57(5):227-32.

14. Ababneh KT. Biopsied gingival lesions in northern Jordanians: A retrospective analysis over 10 years. Int J Periodontics Restorative Dent 2006 Aug; 26(4):387-93.

15 Zarei MR, Chamani G, Amanpoor S. Reactive hyperplasia of the oral cavity in Kerman province, Iran: a review of 172 cases. Br J Oral Maxillofac Surg 2007 Jun;45(4):288-92.

\section{CORRESPONDENCIA}

Antonio Díaz Caballero

Facultad de Odontología. Universidad de Cartagena Campus de la Salud; Barrio Zaragocilla

Cartagena Bolívar

Colombia

Correo electrónico: antoniodiazc@yahoo.com. 